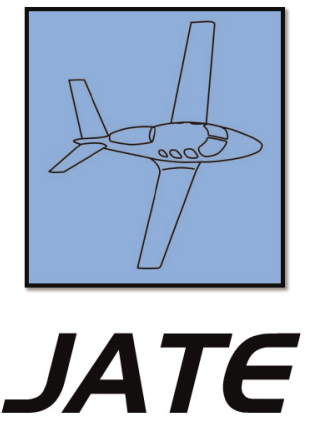

Journal of Aviation Technology and Engineering 4:1 (2014) 11-19

\title{
Increasing Participation in the Pilot Weather Reporting (PIREP) System Through User Interface Design
}

\author{
Stephen M. Casner \\ National Aeronautics and Space Administration
}

\begin{abstract}
Although pilots regard pilot weather reports (PIREPs) as valuable flight planning resources, the number of PIREPs that pilots submit is relatively small. In a previous survey, pilots indicated that submitting PIREPs sometimes requires too much effort, and that they are often unable to recall the information fields required to complete a report. Pilots also indicated that the idea of submitting a PIREP often does not occur to them, and that they feel that other pilots are mainly interested in receiving reports about severe weather. In this study the authors attempt to address obstacles to submitting PIREPs by proposing two alternative designs of a cockpit PIREP interface that: (1) provides pilots with the PIREP form, (2) reduces the process of filling it out to a few button presses, and (3) includes a feature by which pilots can request specific weather reports from other pilots. The request feature reduces the decision to submit a PIREP to deciding whether or not to assist another pilot with a specific request. A series of survey questions probed pilots about how such a system would affect the volume and quality of PIREPs that are submitted.
\end{abstract}

Keywords: pilot weather reports, PIREPs, helping behavior, interface design

\section{Introduction}

Pilot weather reports (PIREPs) are voluntary reports of weather conditions encountered by pilots during flight. The pilot weather reporting system was designed to address two important limitations of the official weather products that are made available to pilots. First, PIREPs can help fill in the gaps between weather observations that are made at fixed locations and at periodic times. Second, PIREPs help pilots continually assess the accuracy of weather forecasts that have been made for their route of flight.

\footnotetext{
About the Author

Stephen M. Casner is a research psychologist at the NASA Ames Research Center. Steve holds a Ph.D. from the Intelligent Systems Program at the University of Pittsburgh, and an FAA Airline Transport Pilot certificate. His research focuses on the impact of technology in the airline and general aviation cockpit. Correspondence concerning this article should be sent to stephen.casner@nasa.gov.
} 
Previous surveys of general aviation pilots found that pilots hold pilot weather reports in high regard, use them regularly when planning flights (Latorella, Lane, \& Garland, 2002; Prinzo, Hendrix, \& Hendrix, 2007; Knecht, 2008), and would like to have more of them available (Casner, 2010; Casner, Murphy, Neville, \& Neville, 2012). However, when queried about the number of pilot weather reports they submit, pilots surveyed by Casner (2010) reported submitting relatively few. During the previous twelve months, although many pilots reported accessing PIREPs before most flights, these same pilots reported submitting only one PIREP for every 36 hours flown. An inventory of the number of pilot weather reports collected and archived by the National Oceanic and Atmospheric Administration (NOAA) confirms pilots reported scant PIREP submissions. Roughly 90 PIREPs were submitted each hour nationwide, or one PIREP for each 42,000 square miles of land area, all altitudes included.

Casner's survey (2010) attempted to identify reasons why pilots contribute so infrequently to a weather reporting system that they hold in such high regard and report drawing from so often. Among the reasons that were identified:

1. Although only $30 \%$ of all pilots indicated that they were often too busy in the cockpit to submit a PIREP, $58 \%$ of all pilots expressed interest in a quicker, easier way of submitting a PIREP.
2. $58 \%$ of all pilots surveyed indicated that it was difficult to remember the information items required to submit a PIREP. Furthermore, $60 \%$ of all pilots indicated that they do not typically carry a copy of the PIREP form with them when they fly.

3. $49 \%$ of all pilots indicated that the idea of submitting a PIREP simply does not often occur to them while flying.

4. A series of survey probes revealed that while pilots were interested in receiving PIREPs about all sorts of weather, they were more likely to submit PIREPs only for weather that is more severe or unexpected.

These survey findings invite the question of whether a pilot interface to the pilot weather reporting system could be designed (or redesigned) in such a way as to overcome these obstacles and to affect an increase in the number of PIREPs that pilots are willing to submit. To help answer this question, mockups of two experimental cockpit weather reporting interfaces were created. Each mockup was designed to isolate the effects of two of the four factors listed above that were shown to influence the number of PIREPs that pilots submit.

\section{A Multifunction Display (MFD) PIREP System}

Figures 1 through 4 illustrate a user interface designed to address the first two obstacles to submitting PIREPs listed

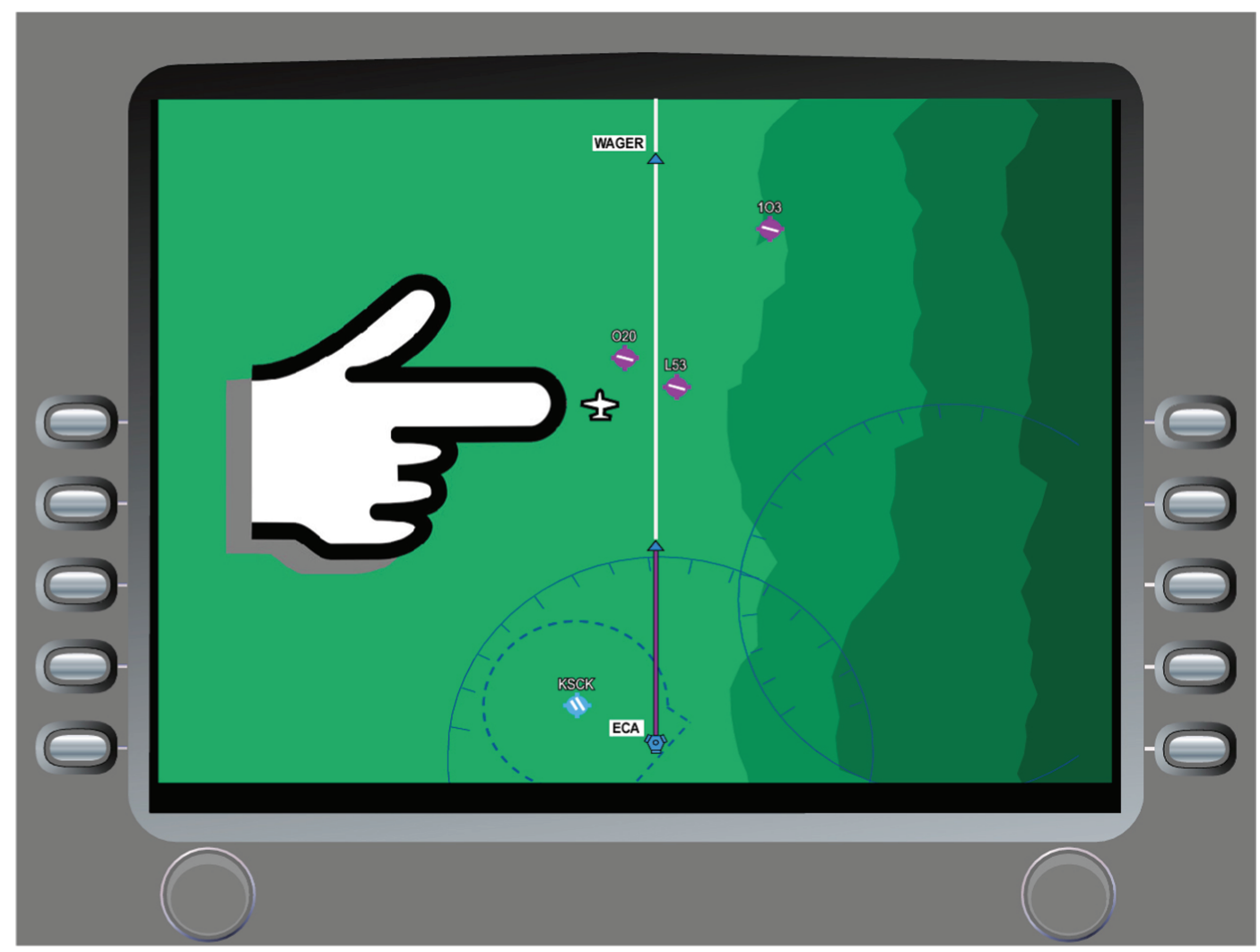

Figure 1. Touch location on MFD to identify location of PIREP. 


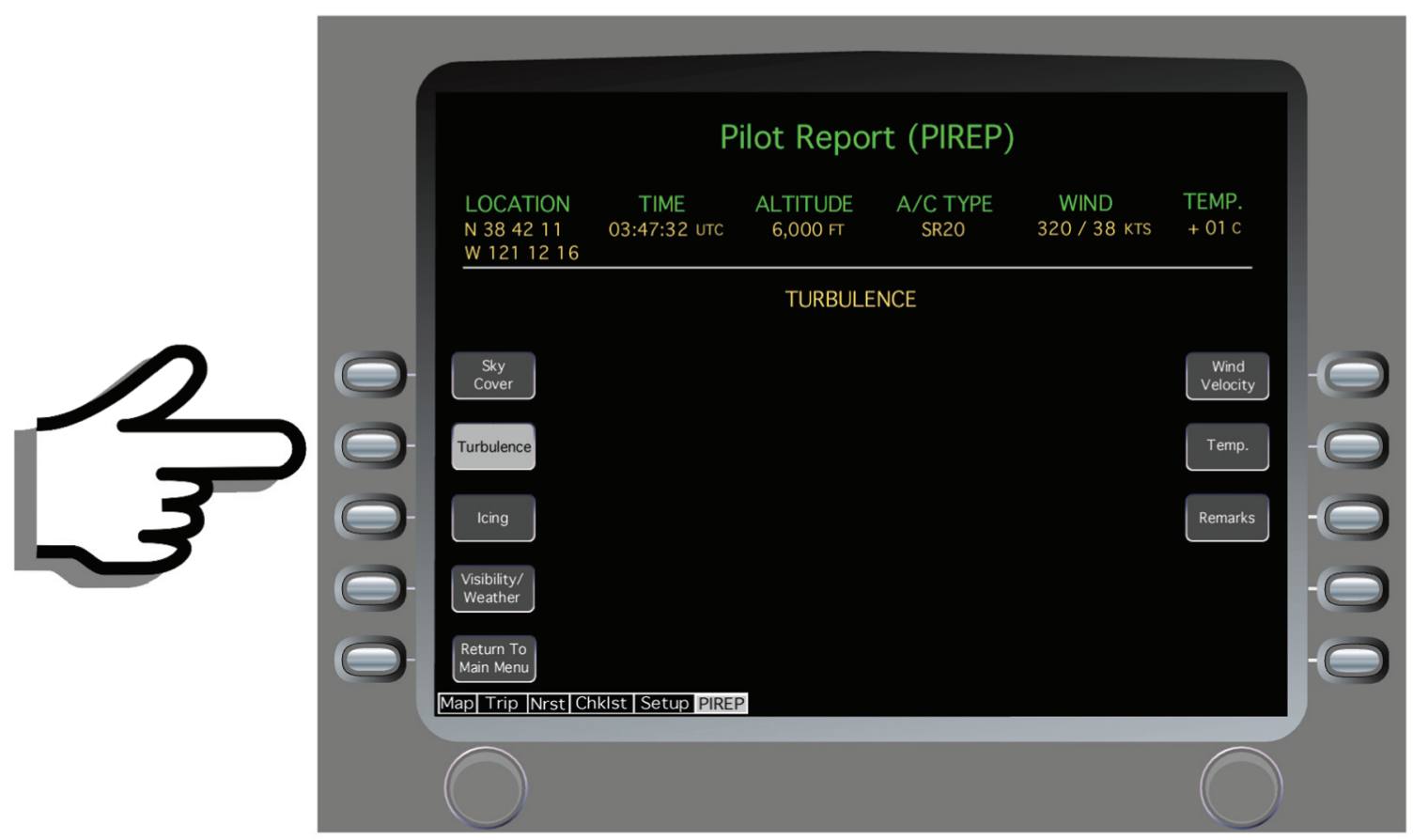

Figure 2. Choose type of weather to report (turbulence).

above: those relating the user's willingness to participate to the system's ease-of-use (Casner, 2010; Starbird \& Palen, 2011). The multifunction display interface reduces the effort required to submit a PIREP to a short sequence of button presses. By presenting buttons for each information field in a pilot weather report, the interface eliminates the need for the pilot to remember which information items are required to submit a PIREP. This system will be referred to as the MFD system.

To submit a PIREP using the MFD system, the pilot starts by touching any location on the map display as shown in Figure 1.

After choosing a location about which to submit a PIREP, the system automatically lists the latitude and

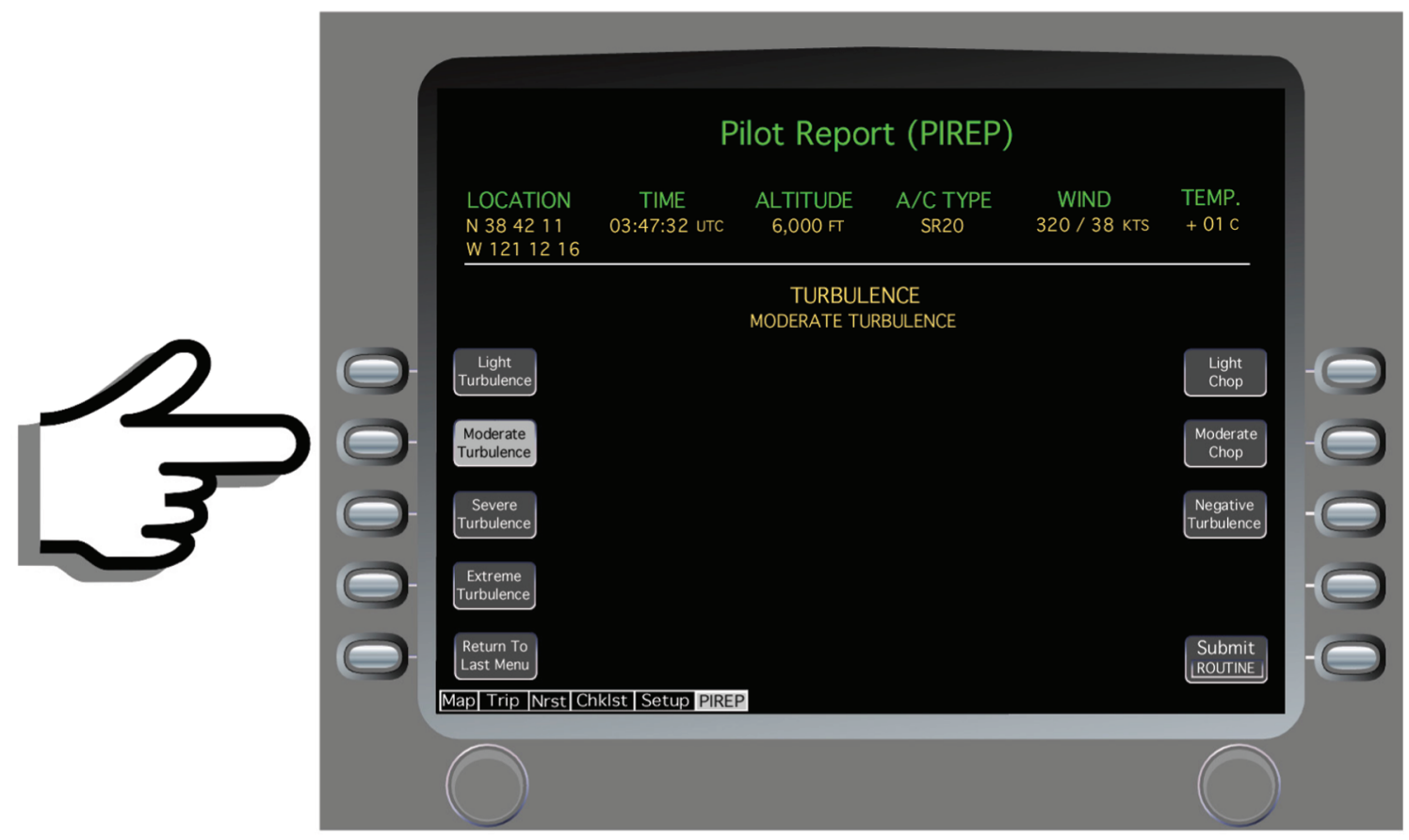

Figure 3. Choose level of turbulence to report (moderate). 


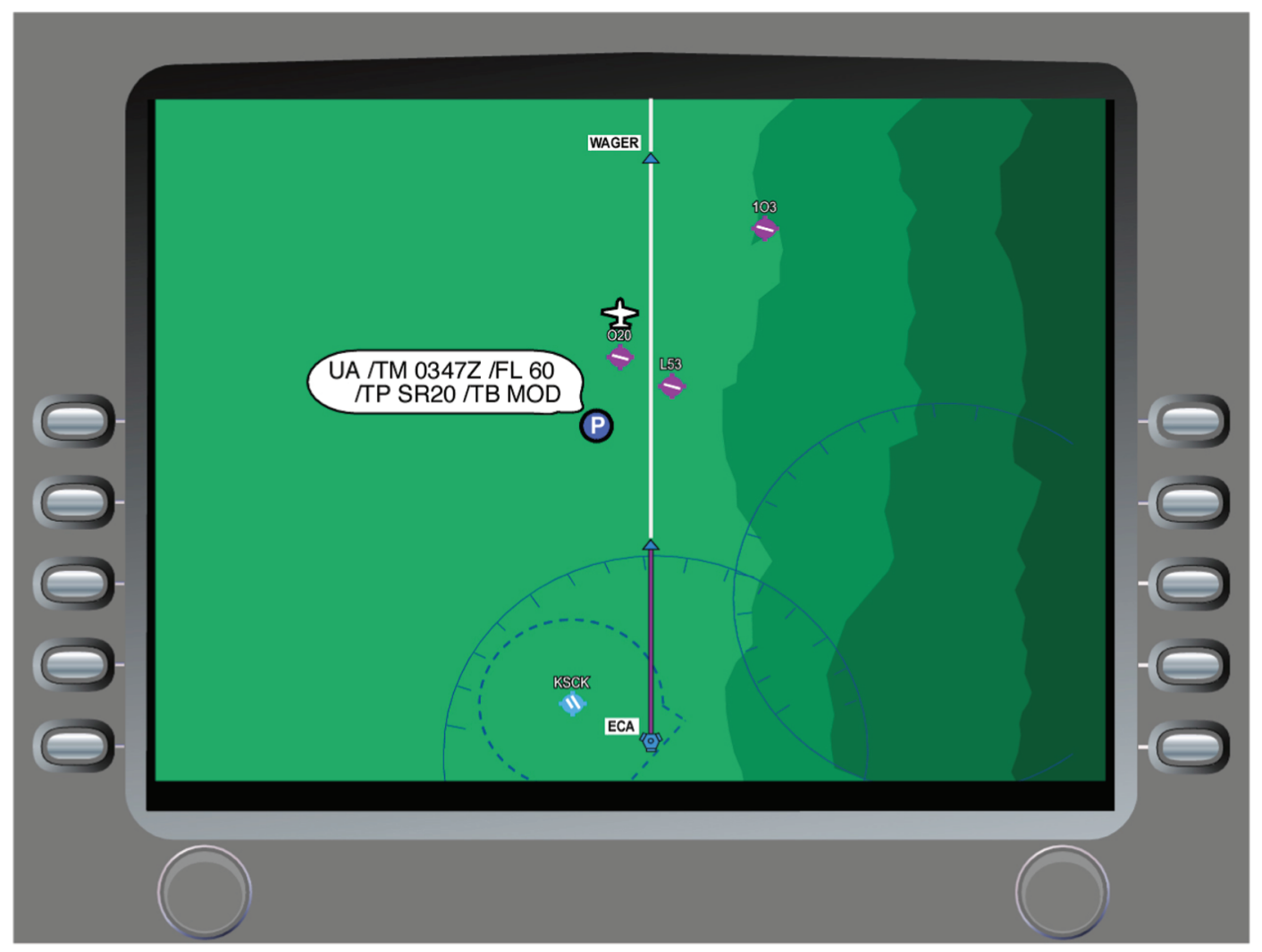

Figure 4. PIREP appears on MFD of participating aircraft.

longitude of the location and notes the current time and aircraft altitude as shown in Figure 2.

Buttons for all remaining reportable weather items then appear on the screen. The pilot can simply press any weather type that he or she would like to report. Turbulence is selected in this example. Once turbulence is selected, choices for the level of turbulence appear as buttons on the screen as shown in Figure 3.

The pilot can choose the level of turbulence to report and then submit the PIREP by pressing the button at the lower right of the screen. Once submitted, a marker for the submitted PIREP will appear on the map displays of all participating aircraft as shown in Figure 4.

The details of the submitted PIREP can be viewed by selecting the marker.

\section{A Request-Based MFD PIREP System}

Figure 5 shows a second experimental system designed to test to what extent pilots might respond to addressing the second two obstacles to submitting PIREPs. By displaying requests for PIREPs submitted by other pilots, this system relieves the pilot from having to think of the idea of submitting a PIREP, and eliminates the need for the pilot to make judgments about which weather phenomena might be of interest to other pilots. An interesting property of this system is that it avoids known problems with peoples' response to unsolicited advice (Boatman, 1987) and changes the act of submitting a pilot weather report to an example of helping behavior: a well-studied psychological phenomenon (Darley \& Latané, 1968; Darley \& Batson, 1973; Aronson, Wilson, \& Akert, 2010). This system will be referred to as the MFD-Request system.

Using the MFD-Request system, pilots are notified when a PIREP request has been made by the appearance of a red symbol on the map display as shown in Figure 5.

Selecting the request symbol on the map reveals that a request for a PIREP about turbulence has been submitted.

Tapping again on the request symbol causes the same PIREP submission screen shown in Figure 2 to appear. Following the same steps to submit a PIREP about turbulence causes the request symbol to change such that it now indicates that a reply has been submitted to the request, as shown in Figure 6.

\section{Method}

A survey was designed to evaluate the two experimental weather reporting systems with respect to how likely pilots would be to use the system to submit PIREPs.

\section{Participants}

One hundred twenty pilots were recruited on a volunteer basis from flight schools, fixed-based operators, and flight safety seminars across the United States. Criteria for 


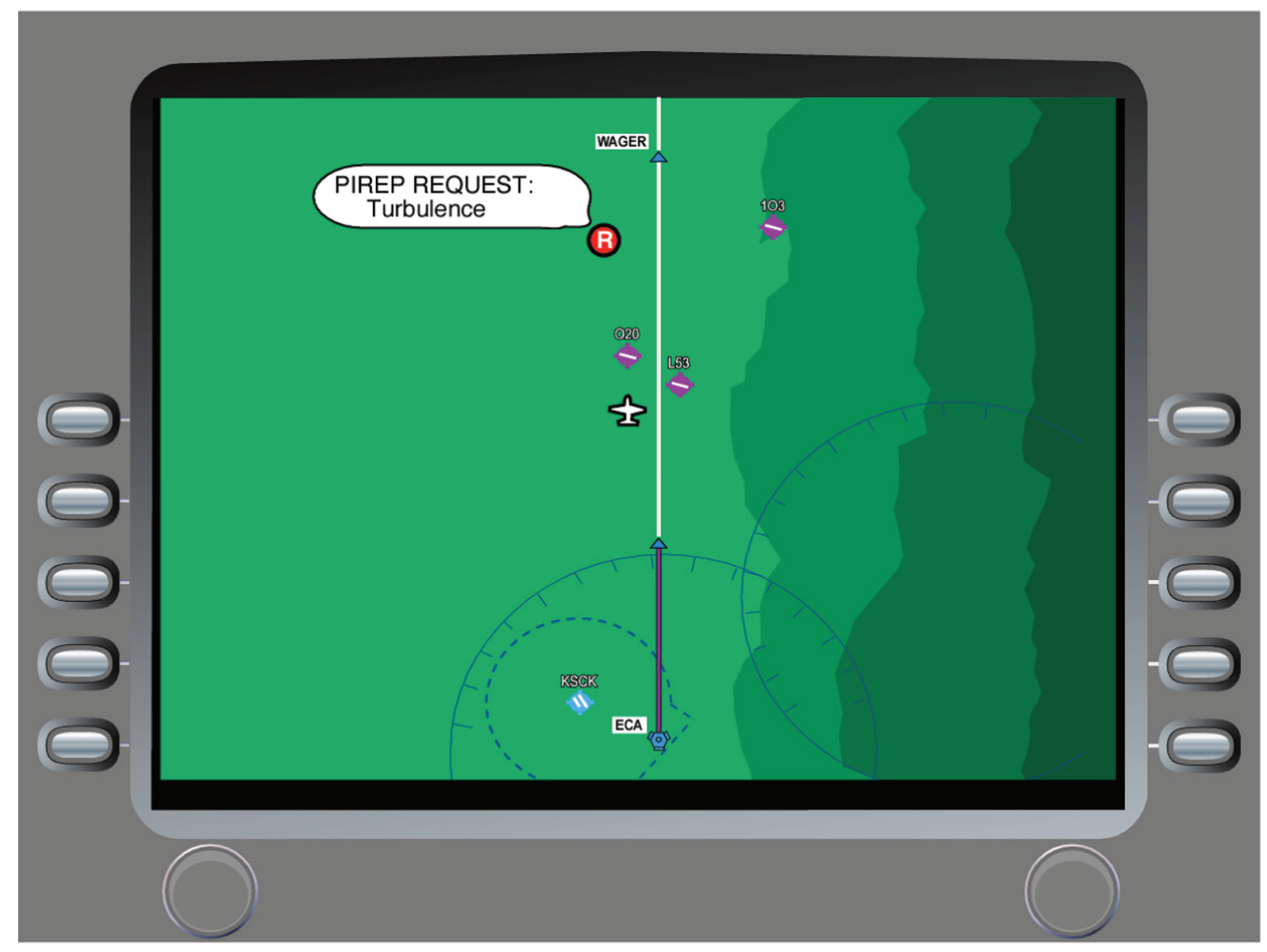

Figure 5. A PIREP request appearing on an MFD.

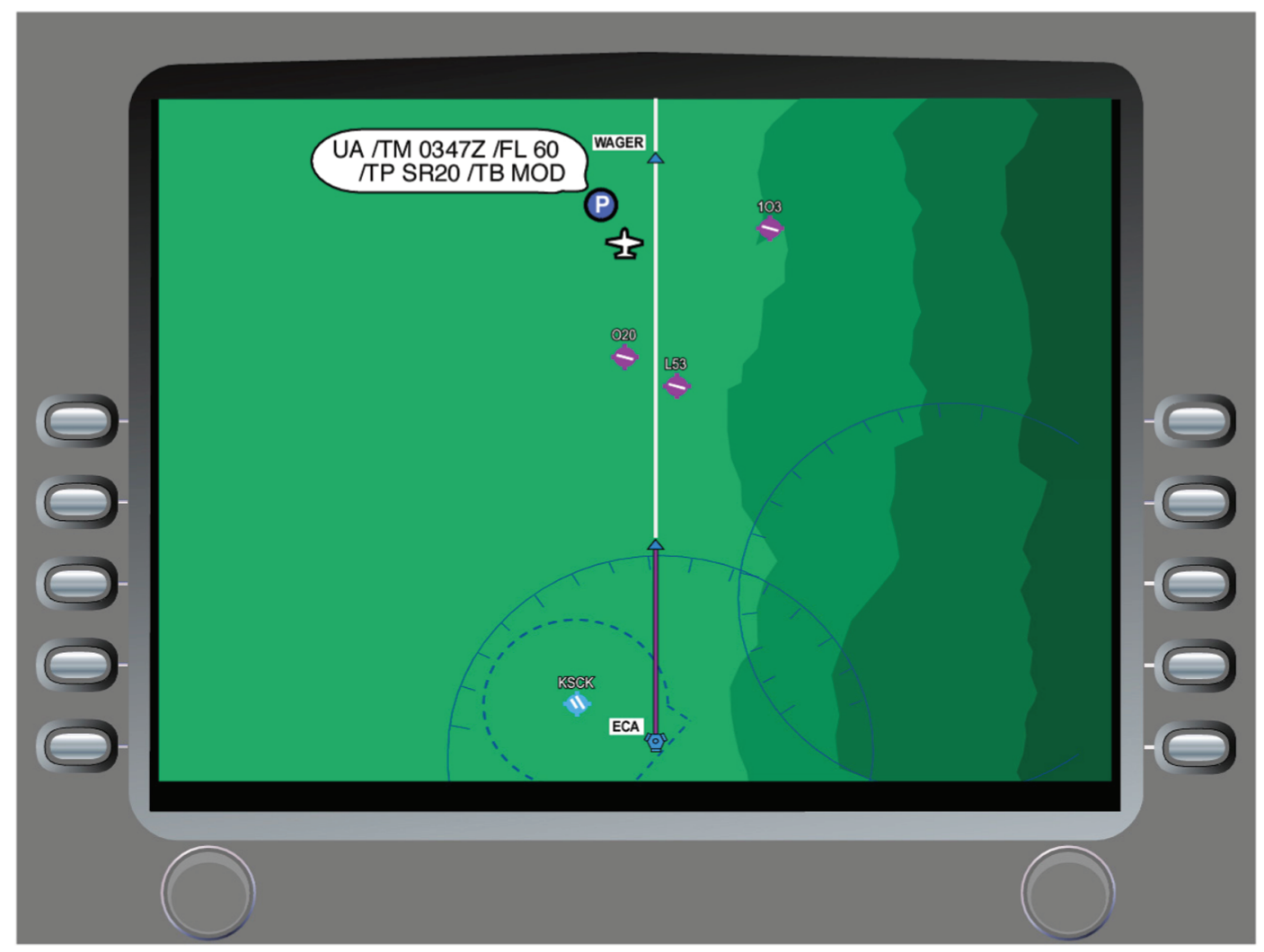

Figure 6. A PIREP submitted in response to a PIREP request. 
inclusion were that each participating pilot held at least an FAA private pilot certificate with an airplane category and class rating. Student pilots were excluded from the sample. Pilots had an average of 3,919 total hours of flight experience $(\mathrm{SD}=5,594, \mathrm{MDN}=1,375)$. Of the pilots who reported the certificates they held, there were 31 airline transport pilots, 54 commercial pilots, 9 private pilots with instrument ratings, and 18 private pilots. 58 pilots reported holding a flight instructor certificate. During the previous twelve months, pilots reported submitting an average of 6.57 PIREPs $(\mathrm{SD}=12.97, \mathrm{MDN}=2)$.

\section{Apparatus}

A paper and pencil survey was used to collect the data. The survey presented pilots with an illustrated description of the two experimental PIREP systems similar to that presented above. Thirty-three Likert-type probes queried pilots about their willingness to submit pilot weather reports when using the current pilot weather reporting system (Flight Watch) and the two experimental weather reporting systems (MFD and MFD-Request). The survey also contained four items that asked participants about their flight experience and certificates and ratings held.

\section{Procedure}

Pilots were approached by an experimenter and asked to participate in the survey. All pilots that agreed to complete the survey did so at the same time they were recruited. There was no time limit for completing the survey and most pilots finished within approximately fifteen minutes. Pilots were told that their survey responses would remain anonymous. Pilots received a pressurized ink capsule "space pen" as compensation for completing the survey.

\section{Results and Discussion}

In response to the statement: "I am satisfied with the pilot weather reporting (PIREP) system we have now," pilots responded neutrally as shown in Figure 7.
These results suggest that at least one half of all surveyed pilots were open to the idea of an improved PIREP system.

In response to the statement: "A system like this would increase the number of PIREPs that are submitted," pilots responded in an almost unanimous agreement when shown each of the two experimental PIREP systems, as shown in Figure 8.

Interestingly, pilots were more likely to agree that the MFD system would result in an increased number of PIREP submissions. A Wilcoxon signed rank test yielded a modest but significant difference between the responses for the two systems: $Z=-3.01$, Asymp. Sig (2-tailed) $=.002$. On the survey, 88 pilots rated the two systems as having a similar effect on quantity, 25 pilots rated the MFD system as having a greater effect, while 6 pilots rated the MFDRequest system as having a greater effect. Clearly, not every pilot felt that they would respond to requests made by other pilots. To more directly examine pilots' willingness to help other pilots, respondents were presented with the statements: "I am more likely to submit a response to a request made by another pilot" and "I would try to respond to PIREP requests made by other pilots." As shown in Figure 9, responses to these two probes were highly positive but not unanimous.

Despite a high overall agreement, the data in Figure 9 suggest that some people are more willing to help than others. There were no significant correlations between total flight time, certificates held, and pilots' reported willingness to respond to PIREP requests. The following statement explored one other objection to responding to PIREP requests: "I am worried that a system like this would be used by some pilots as a substitute for checking weather prior to departing.": $26 \%$ of all pilots agreed or strongly agreed with the statement, while $44 \%$ disagreed or strongly disagreed. There were no significant correlations between pilots' responses to this probe and their reported willingness to respond to PIREP requests.

Pilots also responded to the statement: "A system like this would increase the quality of PIREPs that are available to pilots" with near unanimous agreement, and there was

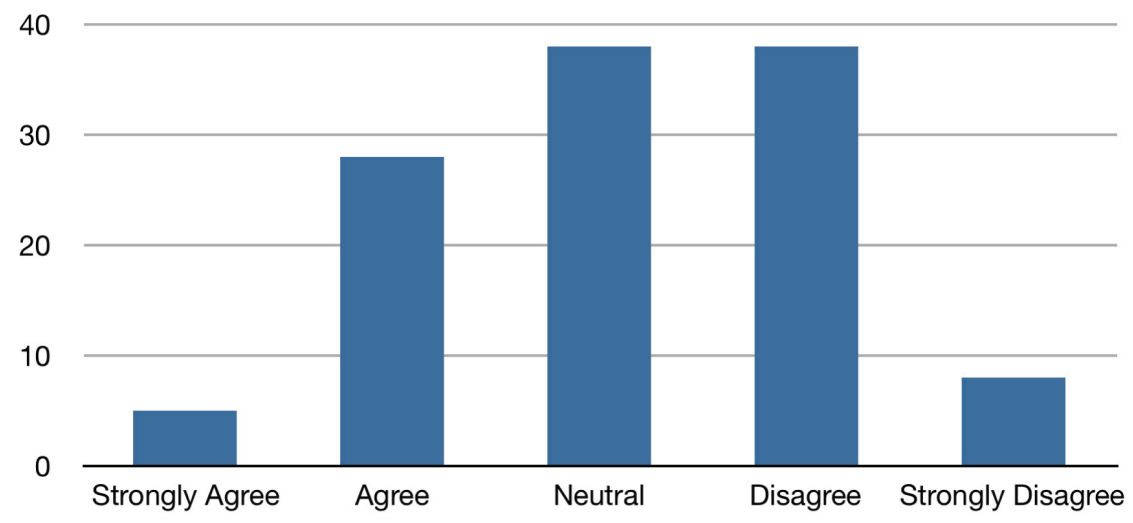

Figure 7. Pilots' satisfaction with the current PIREP system. 


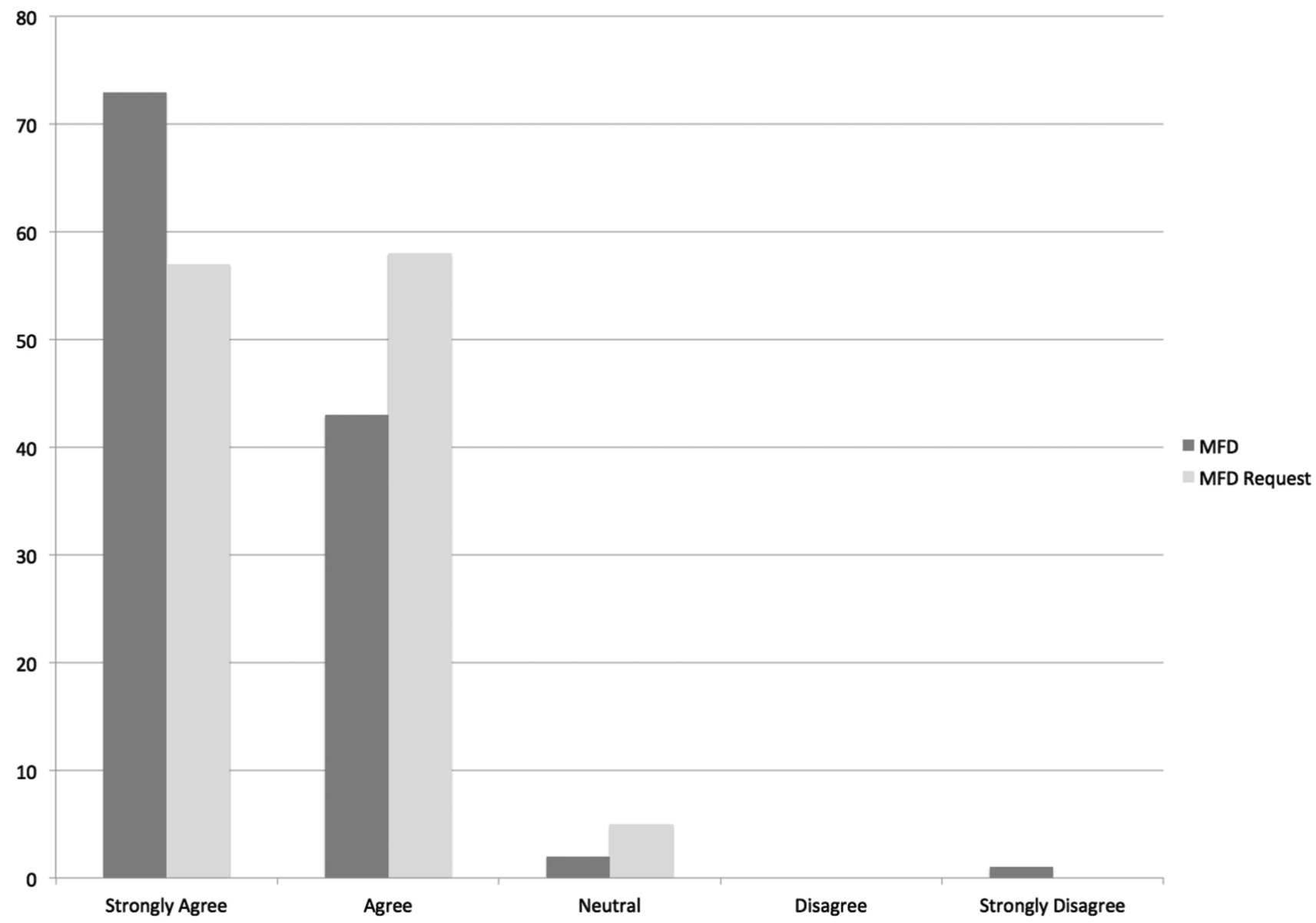

Figure 8. Responses to "A system like this would increase the number of PIREPs that are submitted" for each of the two PIREP systems.

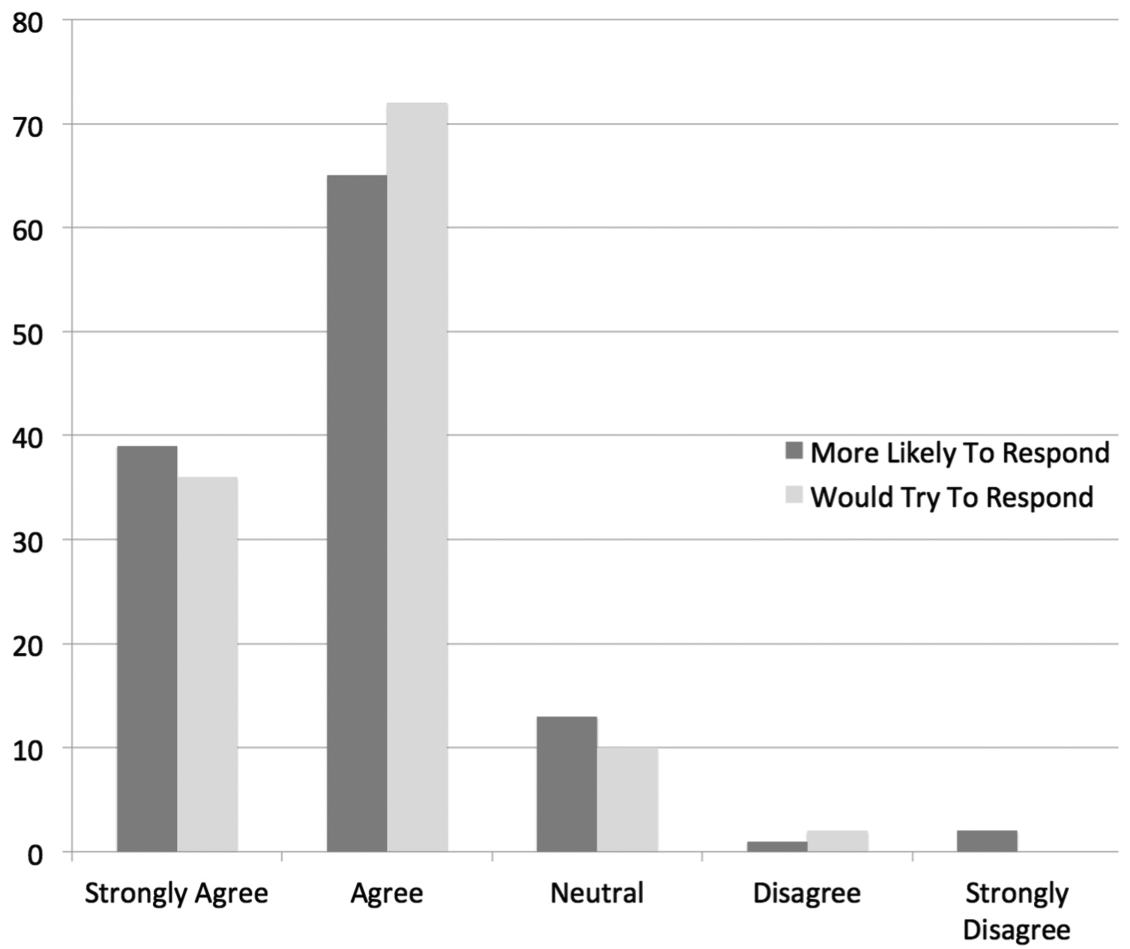

Figure 9. Responses to two probes about pilots' willingness to submit PIREPs in response to requests made by other pilots. 
no significant difference between the two systems: MFD: 87\%, MFD-Request: $88 \%$.

One limitation of survey probes such as the ones used above is that respondents can sometimes offer a general agreement to perform an action that may not materialize in practice. While the researchers were not able to measure usage of these systems in practice, pilots were asked about their willingness to use the systems to submit PIREPs under circumstances that were described more concretely. Twenty-four survey items asked pilots to indicate the frequency at which they would submit a PIREP using the existing weather reporting system and the two experimental weather reporting systems described above, for two different weather phenomena (turbulence and a cloud layer), when the weather was and was not forecasted. Table 1 lists these 24 survey items along with pilots' responses to them.

To test the effects of the pilot weather reporting system used, the type of weather observed, and whether or not the weather had been forecasted, the number of pilots who responded with "Always" or "Often" were summed for each of the 24 cases. A 3-way analysis of variance (ANOVA) revealed no significant interactions between the three variables. A main effect for the weather reporting system variable was observed: $\mathrm{F}(2,8)=25.79, \mathrm{p}<.0001$. Post hoc tests revealed that the Flight Watch, MFD, and MFD-Request systems significantly differed from each other, and in increasing order of willingness to submit PIREPs. A main effect of the forecasted variable was also observed: $\mathrm{F}(2,8)=11.02, \mathrm{p}<.0001$. Pilots reported being more willing to submit PIREPs for weather that was not forecasted. No significant main effect was observed for the Weather Type variable (turbulence vs. cloud layer).

Despite pilots' reported willingness to submit PIREPs more often using the two experimental systems, the effect is far from total. Twenty percent of surveyed pilots would still not agree that they would submit a PIREP for an unforecasted cloud layer, while $9 \%$ did not agree that they would submit a PIREP for unforecasted moderate turbulence.

Table 1

Survey items and pilots' responses

\begin{tabular}{|c|c|c|c|c|c|}
\hline & Always & Often & Sometimes & Rarely & Never \\
\hline \multicolumn{6}{|c|}{ Moderate Turbulence: Moderate Turbulence Forecasted } \\
\hline Flight Watch & 2 & 15 & 34 & 46 & 22 \\
\hline MFD & 14 & 54 & 32 & 12 & 4 \\
\hline MFD-Request & 29 & 53 & 27 & 3 & 3 \\
\hline \multicolumn{6}{|c|}{ Negative Turbulence: No Turbulence Forecasted } \\
\hline Flight Watch & 1 & 5 & 13 & 44 & 56 \\
\hline MFD & 8 & 22 & 40 & 24 & 22 \\
\hline MFD-Request & 20 & 47 & 27 & 10 & 12 \\
\hline \multicolumn{6}{|c|}{ Negative Turbulence: Moderate Turbulence Forecasted } \\
\hline Flight Watch & 2 & 16 & 26 & 53 & 22 \\
\hline MFD & 12 & 49 & 37 & 12 & 6 \\
\hline MFD-Request & 28 & 52 & 23 & 8 & 5 \\
\hline \multicolumn{6}{|c|}{ Moderate Turbulence: No Turbulence Forecasted } \\
\hline Flight Watch & 9 & 33 & 35 & 26 & 16 \\
\hline MFD & 37 & 58 & 13 & 5 & 3 \\
\hline MFD-Request & 49 & 52 & 8 & 3 & 4 \\
\hline \multicolumn{6}{|c|}{ Cloud Layer That Was A Factor: Not Forecasted } \\
\hline Flight Watch & 1 & 25 & 38 & 34 & 22 \\
\hline MFD & 16 & 63 & 31 & 5 & 3 \\
\hline MFD-Request & 40 & 55 & 15 & 5 & 3 \\
\hline \multicolumn{6}{|c|}{ Cloud Layer That Was A Factor: Forecasted } \\
\hline Flight Watch & 1 & 8 & 11 & 59 & 41 \\
\hline MFD & 10 & 21 & 41 & 34 & 12 \\
\hline MFD-Request & 26 & 43 & 27 & 12 & 8 \\
\hline \multicolumn{6}{|c|}{ Clear Sky: Cloud Layer Forecasted } \\
\hline Flight Watch & 1 & 6 & 26 & 43 & 44 \\
\hline MFD & 9 & 33 & 45 & 20 & 11 \\
\hline MFD-Request & 27 & 48 & 26 & 7 & 10 \\
\hline \multicolumn{6}{|c|}{ Clear Sky: Clear Sky Forecasted } \\
\hline Flight Watch & 1 & 4 & 4 & 35 & 75 \\
\hline MFD & 6 & 10 & 18 & 44 & 39 \\
\hline MFD-Request & 18 & 27 & 24 & 24 & 24 \\
\hline
\end{tabular}




\section{Conclusion}

Pilots were presented with two experimental pilot weather reporting systems designed to address some of the reasons why pilots submit relatively few PIREPs. Pilots were asked about their beliefs about how the experimental systems would likely affect the number and quality of pilot weather reports submitted, and then asked to gauge their willingness to submit pilot weather reports for specific weather phenomena. The results suggest that the two experimental systems would each result in an increase in both the quantity and quality of PIREPs submitted.

Pilots' reported willingness to respond to PIREP requests, even when requested by other pilots, and even for unforecasted weather that was a factor for their flight, was far from unanimous. There are a number of factors that might still prevent pilots from using either of the experimental weather reporting systems. Casner (2010) found that another reason why pilots shied away from submitting PIREPs was a lack of confidence in their ability to correctly classify or identify the weather phenomena they saw.

Even if pilots reported being more willing to respond to PIREP requests made by other pilots, studies of helping behavior in the general population suggest that other factors might reduce the incidence of pilots responding to requests. A well-known "bystander effect" has been demonstrated in which responses are more likely when a single bystander is present than when more than one potential helper is present. When PIREP requests appear on the screens of many pilots, a familiar "diffusion of responsibility" may occur: each pilot leaving the chore of making a response to the other available pilots. The diffusion of responsibility effect is known to be a strong one and studies have demonstrated it in situations ranging from helping an injured person (Darley \& Latané, 1968) to leaving restaurant tips when a group of diners is present (Freeman et al., 1976). Some studies have even measured the effect of time pressure on potential helpers (Darley \& Batson, 1973).

Allowing pilots to both request and submit pilot weather reports establishes a two-way line of communication among pilots. This capability raises the question of whether or not there is other information that might be shared among pilots. A system that permitted more information exchange among pilots, both formal and informal, would approximate the capability of a social media website such as Facebook or Twitter. Studies of the use of social media sites in response to unusual events have demonstrated many interesting forms of emergent human behavior. Individuals often exhibit remarkable levels of helpfulness, social connection, organization, and collective action (Starbird, 2012).

The greatest limitation of the study was reliance upon pilots' informal estimations of how likely they were to use each of the two systems considered. A more convincing study would examine pilots' usage of a real cockpit system during everyday flight operations. Such a study poses a number of challenges for the researcher. First, studying pilots' use of panel-mounted systems such as those described here present a bootstrapping problem: such systems would need to be designed, built, and certified for use during flight before embarking on the collection of empirical evidence to show that they are effective. Second, it is widely believed that the introduction of new technology systems can lead to a temporary "novelty effect" that can affect users' behavior throughout an extended period of initial use (Clark \& Sugrue, 1991). A true empirical evaluation of a PIREP system may require studying pilots over periods of many months in order to observe their ultimate level of acceptance and use of such a system. Prior to solving these difficult problems, the authors measured pilots' initial feelings about an improved interface to the pilot weather reporting system.

\section{References}

Aronson, E., Wilson, T. D., \& Akert, R. M. (2010). Social psychology. Boston, MA: Prentice-Hall.

Boatman, D. (1987). A study of unsolicited advice. Working Papers in Educational Linguistics, 3(1), 35-60.

Casner, S. M. (2010). Why don't pilots submit more pilot weather reports (PIREPs)? International Journal of Aviation Psychology, 20(4), 347374. http://dx.doi.org/10.1080/10508414.2010.487015

Casner, S. M., Murphy, M. P., Neville, E. C., \& Neville, M. R. (2012). Pilots as weather briefers: The direct use of aviation weather products by general aviation pilots. International Journal of Aviation Psychology, 22(4), 367-381. http://dx.doi.org/10.1080/10508414.2012.718241

Clark, R. E., \& Sugrue, B. M. (1991). Research on instructional media, 1978-1988. In G. J. Anglin (Ed.), Instructional technology: Past, present, and future (pp. 327-343). Englewood, CO: Libraries Unlimited.

Darley, J. M., \& Latané, B. (1968). Bystander intervention in emergencies: Diffusion of responsibility. Journal of Personality and Social Psychology, 8(4), 167-188. http://dx.doi.org/10.1037/h0025589

Darley, J. M., \& Batson, C. D. (1973). From Jerusalem to Jericho: A study of situational and dispositional variables in helping behavior. Journal of Personality and Social Psychology, 27(1), 100-108. http://dx.doi. org/10.1037/h0034449

Freeman, S., Walker, M. R., Borden, R., \& Latané, B. (1976). Diffusion of responsibility and restaurant tipping: Cheaper by the bunch. Personality and Social Psychology Bulletin, 1(4), 584-587. p://dx.doi.org/10.1177/ 014616727500100407

Knecht, W. R. (2008). Use of weather information by general aviation pilots, Part I, Quantitative: Reported use and value of providers and products (DOT/FAA/AM-08/6). Oklahoma City, OK: Federal Aviation Administration.

Latorella, K., Lane, S., \& Garland, D. (2002). General aviation pilots' perceived usage and valuation of aviation weather information sources. NASA Technical Memorandum TM-2002-211443.

Prinzo, O. V., Hendrix, A. M., \& Hendrix, R. (2007). An analysis of preflight weather briefings (DOT/FAA/AM-07/4). Washington, DC: Federal Aviation Administration.

Starbird, K. (2012). Crowdwork, crisis, and convergence: How the connected crowd organizes information during mass disruption events (Doctoral dissertation). University of Colorado at Boulder.

Starbird, K. \& Palen, L. (2011). "Voluntweeters": Self-organizing by digital volunteers in times of crisis. Proceedings of the ACM 2011 Conference on Human Factors in Computing Systems (CHI 2011), Vancouver, BC. 